\title{
Motivation and Language Learning
}

\author{
Bo Wang \\ College of Foreign Languages \\ Daqing Petroleum Institute \\ DaQing 163318, China
}

\begin{abstract}
Motivation is one of the important factors that influences English learning achievement. So in order to help the students to maintain a proper strength in English learning motivation is very necessary for the teachers in the daily teaching procedure.

This paper discusses the issue of motivation in foreign language learning in four main sections .It starts with the background information. Then it is concerned with the motivation issues in EFL in China, and finally, tries to provide some advices for teachers to enhance students' motivation in English teaching for non-English majors at tertiary level.
\end{abstract}

Keywords: Motivation, Language learning, EFL in China

\section{Introduction}

\subsection{Background about motivation}

With regard to research into motivation, numerous studies have been carried out by researchers as well as language teachers. The first one, by Gardner and Lambert (1972), is regarded as one of the well-known studies of motivation in language learning, and the other two, by Brown (1980) and Harmer (1983) respectively, also have received widespread attention.

As we all know, motivation is one of the most important factors that will influence students' English achievements or Performance. It has a close relationship with students' success or failure in English teaching in college. Therefore, Teachers must pay more attention to this aspect. As Gardner (1985) emphasized that the motivation constructed the primary factor to influence students on English learning. He believed that motivation for language learning can not only include goal orientation but the combination of effort, desire to achieve the goal of learning the language and favorable attitudes toward learning the language.

A number of studies conducted by Gardner and Lambert on instrumental and integrative motivation show how each appears to relate to language proficiency. Whereas in their earlier studies, it appeared that integrative motivation was superior to instrumental, their later investigations demonstrated that in situations where the practical value of the second language is necessary.

In addition to the study by Gardner and Lambert, several empirical studies by other researcher also proved that both types of motivation have positive effects on the level of proficiency achieved by different learners and one type may be more effective than the other under certain conditions. Nowadays in China, as English is viewed as a utilitarian tool for science, technology, national development and modernization as well as a key element in furthering a career, even though students approach the learning of English with instrumental motivation, many of them are very successful in developing proficiency in English . This indicates that the relative importance of instrumental or integrative motivation depends to a large extent on the context in which a new language is learned.

\subsection{Task motivation}

Another research on motivation was carried out by Brown, He especially identified one type of motivation--Task motivation. Task motivation is drive for performing particular learning tasks, that is, if the teacher designs appropriate tasks which will lead students to successful performances, such constantly pleasant and rewarding experiences will provide students with increasing confidence and consequently, they will gradually develop a liking for second language learning. So learning a foreign language obviously requires some types of motivation. 


\subsection{Extrinsic and intrinsic motivation}

Harmer (1983) categorized motivation into two major types; extrinsic and intrinsic motivation. Extrinsic motivation concerns the factors outside the classroom. It essentially consists of two sub -types: instrumental and integrative motivation which corresponds to Gardner and Lamber's sense of motivation .Intrinsic motivation, on the contrary, concerns the factors inside the classroom. To them, what happens in the classroom will be of vital importance in developing their motivation, Intrinsic motivation is primarily made up of two parts; task and situational motivation which is as the same as Brown's point of view.

However, no matter how motivation has been classified, all kinds of motivation work in the second language learning context, and each kind contributes to the learners' progress in different ways and to different degree, It is hard to say which is the most effective since they are sometimes overlapping with one another.

\section{Issues of motivation in EFL in China}

It is well known that in China, there has also been an increasing awareness and interest among researchers and teachers alike in the role of motivation in foreign language learning, In 1989, Zhang Bensheng did research on 70 outstanding students including English and non-English majors from seven key colleges and universities in Wuhan. The results showed that the achievements of the students had a close relationship with their motivation. All of the students possessed some kind of motivation for learning English: some were intent on making a useful contribution to society, while others wanted to improve their professional prospects .Such students seemed to have instrumental motivation. Still others were interested in the learning environment or encouraged by their previous success. They had task and situational motivation. A few of them were attracted by the target culture; they were integrally motivated.

Nowadays, most students in key universities have high motivation to learn English well. because a good level of English will help them more considerably to obtain better jobs, especially those in companies or joint ventures which have international connections; to read technical materials , and to study abroad. At this point, a teacher should intend to suggest some principles we can make use of in foreign language teaching process.

\section{Some ways to the enhancement of students' motivation}

\subsection{The student-centered class}

In China, college English teaching follows a prescribed syllabus, which consists of EGP (English for General Purposes) and ESP (English for Specific Purposes) stages. The EGP stage is divided into six bands, namely college English Bands 1-6. In the ESP stage, students are required to read and comprehension books or articles related to their specialties. In each band, there are specific requirements for vocabulary, grammar knowledge and students' reading skills.

After a careful consideration, we can see the actual reasons lying in our teaching method. The classroom is the place where the learning process goes on. Only when students are involved in the class activities will they have the interest in learning the language. The teacher, instead of requiring students to recite language points and learn vocabulary by heart, should introduce some elements from communicative approach, that is, providing students with enough opportunities to practice the new language and learn how to use it in actual context. Rather than domination the class, the teacher should initiate some questions for students to discuss, encourage students to ask each other questions, or even to argue about with each other about some controversial issues. During the periods of teaching, the teacher should present an element of challenge to the students, and the challenge can lead to higher motivation and more effective results.

\subsection{Developing Students Cultural Empathy}

In our own teaching practice, we may find there is one point deserving our attention: some students with instrumental motivation may lose it when they consider what they have acquired to be sufficient to realize their goals. Since students of this kind usually have little or no personal interest in learning the language, they may have a negative attitude about learning the language.

As we all know that language and culture are so interlinked that they cannot be separated in the process of foreign language teaching. It seems reasonable to assume that development of positive attitudes toward the culture and the native speakers of the language we teach will carry over into integrative motivation for learning the language

\subsection{Encouraging and praising students timely}

Encouragement and praise should be seen as a reward. Learning English is a hard work needs reward. This reward can be successful communication or complement of a required task either .As we know, for the majority of students, to learn English well is no easy job, it requires countless practice and great effort .If students' hard work and progress are ignored by the teacher, they may feel disappointed, or even lose their heart. On the contrary, if students' efforts and progress are praised timely by the teacher, they will expend more efforts and consequently make greater progress in learning the language.

Nevertheless, excessive praise can cause uneasiness to the praised and constitute an implied criticism to the rest, which 
can do more harm than good. Proper praise and encouragement help students feel successful, gain confidence in their ability. Since praise costs nothing of the giver, it is a cheap, easy but effective way to foster and reinforce students' motivation for learning

\section{Conclusion}

From above we can see as a teacher, we should try our best to stimulate students' enthusiasm in learning English in order to improve teaching efficiency. As for students, a best choice for them is to follow the instructions and the suggestions when they study, and they had better adjust their cognition, strategies to their studies.

Lastly, I want to stress the point that motivation is not the single factor influencing students' foreign language proficiency. Other factors, such as aptitude, attitude, learning cognitive style, and learning strategies, also play important roles in foreign language learning process. In this paper, we have simply attempted to explore motivation and to provide teachers with some approaches to coping with studies. We hope that the discussion will help language teachers have better and more effective approaches to classroom teaching in order to improve students' foreign language.

\section{References}

Cohen, A. (1990). Second Language Learning: Insights for learners, Teachers, and Researchers. New York: Newbury House/Harper \& Roy.

Cook, V. (1991). Second Language Learning and Language Teaching. London Edward Arnold.

Dulay, H. C. \& Burt, M, K. (1982). Language Two. Oxford University Press.

Hansen, R. A. (1997). Motivation in Education. New York: Academic Press.

Skehan, P. (1989). Individual Differences in Second-Language learning. London: Edward Arnold. 